\title{
NILAI-NILAI PENDIDIKAN KARAKTER DALAM TRADISI APITAN MASYARAKAT SINGOCANDI KUDUS
}

\author{
Muchamad Munawir Asyari, Erik Aditia Ismaya, dan Muhammad Noor Ahsin
}

Universitas Muria Kudus

Email: munawir.asyari@gmail.com

\section{Info Artikel}

\section{Sejarah Artikel:}

Diserahkan 19 Januari 2021

Direvisi 09 Februari 2021

Disetujui 10 Februari 2021

\section{Keywords:}

Character Education,

Apitan Tradition,

Singocandi

\begin{abstract}
The purpose of this study is to analyze the reasons for the Singocandi Village community in implementing the Apitan tradition and to analyze the values of character education in the Apitan tradition of the Singocandi Village community.

The research was conducted using a qualitative approach with descriptive types and field study methods. The research was conducted in Singocandi Village, Kota District, Kudus Regency. The data collection techniques are through observation, interviews, and document study. Primary data sources were obtained from the results of observations and interviews with the pundhen caretaker Mbah Buyut Punjol, village officials, and the traditional committee of Apitan Alms Earth, Singocandi Village. As for the secondary data sources, researchers were obtained from supporting documents. Testing the validity of the data used the technique and source triangulation techniques. In this study, technical triangulation was carried out by combining data received from observations, interviews, and documents. Meanwhile, source triangulation was carried out by combining interview data from various sources.

The results showed that the reason Singocandi Village people still carry out the Apitan tradition is as a form of preserving the nation's cultural heritage and to respect the struggles of the ancestors of the Indonesian nation. In the Apitan tradition there are also character education values such as religious, honest, tolerance, discipline, creative, love for the country, social care, and caring for the environment that need to be instilled in the nation's future generations. Therefore, this tradition must be preserved and introduced to the future generations of the nation.
\end{abstract}

\begin{abstract}
Abstrak
Tujuan penelitian ini yaitu untuk menganalisa alasan masyarakat Desa Singocandi dalam melaksanakan tradisi Apitan dan menganalisa nilai-nilai pendidikan karakter dalam tradisi Apitan masyarakat Desa Singocandi.

Penelitian dilakukan menggunakan pendekatan kualitatif dengan jenis deskriptif serta metode studi lapangan. Penelitian dilakukan di Desa Singocandi, Kecamatan Kota Kabupaten Kudus. Adapun teknik pengumpulan datanya melalui observasi, wawancara, serta studi dokumen. Sumber data primer didapatkan dari hasil observasi dan wawancara kepada juru kunci pundhen Mbah Buyut Punjol, perangkat desa, serta panitia tradisi Apitan Sedekah Bumi Desa Singocandi. Sedangkan untuk sumber data sekunder peneliti diperoleh dari dokumen pendukung. Pengujian keabsahan data digunakan teknik triangulasi teknik dan sumber. Dalam penelitian ini triangulasi teknik dilakukan dengan cara menggabungkan data yang diterima dari hasil observasi, wawancara, dan dokumen. Sementara triangulas sumber dilakukan dengan menggabungkan data hasil wawancara dari berbagai narasumber. Hasil penelitian menunjukkan bahwa alasan masyarakat Desa Singocandi masih melaksanakan tradisi Apitan yaitu sebagai wujud untuk melestarikan warisan budaya bangsa serta untuk menghargai perjuangan para leluhur bangsa Indonesia. Dalam tradisi Apitan juga terdapat nilai pendidikan karakter seperti religius, jujur, toleransi, disiplin, kreatif, cinta tanah air, peduli sosial, dan peduli lingkungan yang perlu ditanamkan kepada generasi penerus bangsa. Oleh sebah itu tradisi ini wajib dilestarikan dan dikenalkan kepada generasi muda penerus bangsa.
\end{abstract}




\section{Muchamad Munawir Asyari, Erik Aditia Ismaya, dan Muhammad Noor Ahsin \\ NILAI-NILAI PENDIDIKAN KARAKTER DALAM TRADISI APITAN MASYARAKAT ... WASIS : Jurnal Ilmiah Pendidikan. Volume 2 Nomor 1 Mei 2021, hlm. 34-40}

\section{PENDAHULUAN}

Di jaman milenial sekarang banyak terjadi degredasi karakter pada masyarakat, hal itu dapat dilihat dengan banyaknya kasus tindak kekerasan, hoax (berita bohong), tindak suapmenyuap, bullying (Putri, Ismaya, and Fardani 2021), dan korupsi. Parahnya hal itu terjadi bukan hanya pada kalangan bawah namun juga kalangan elite.

Degredasi karakter yang terjadi pada masyarakat dapat dibenahi melalui pendidikan karakter, dimana nantinya seorang individu akan mendapat arahan agar memiliki karakter yang lebih baik. Penelitian Romadlon dan Ismaya (2015) mengungkap bahwa terdapat ciri khas dalam proses pembentukan karakter pemuda Indonesia melalui Gerakan Pramuka pada tiap ambalan yang diteliti berupa modelnya, prosesnya dan karakter yang ingin dibentuk. Sementara itu riset Kurniasih dan Sani (2017) menyebut bahwa untuk membimbing seseorang menjadi orang baik sehingga mampu memfilter pengaruh yang tidak baik dapat menggunakan pendidikan karakter sebagai alat untuk membimbing orang menjadi lebih baik.

Karakter yang baik merupakan karakter yang sesuai dengan nilai-nilai luhur bangsa Indonesia. Pusat Kurikulum Badan Penelitian dan Pengembangan Kementerian Pendidikan Nasional (2011) telah mengidentifikasi 18 nilai pembentuk karakter sebagai berikut: (1) religius, (2) jujur, (3) toleransi, (4) disiplin, (5) kerja keras, (6) kreatif, (7) mandiri, (8) demokratis, (9) rasa ingin tahu, (10)semangat kebangsaan, (11) cinta tanah air, (12) menghargai prestasi, (13) bersahabat/ komunikatif, (14) cinta damai, (15) gemar membaca, (16) pedul lingkungan, (17) peduli sosial, (18) tanggung jawab.

Pendidikan karakter tidak hanya bisa dilakukan melalui lingkungan sekolah namun dapat juga dilakukan melalui lingkungan masyarakat, seperti melalui kegiatan tradisi budaya. Sebagaimana telah kita ketahui bahwa Indonesia memiliki beragam tradisi yang dilestraikan oleh masyarakat dan dilaksanakan secara turun menurun.

Warisan tradisi budaya bisa dijadikan sarana untuk menanamkan nilai-nilai pendidikan karakter dan sebagai identitas sebuah daerah. Pambudi (2014) mengungkapkan bahwa tradisi merupakan gambaran sikap dan perilaku manusia yang telah berproses dalam waktu lama dan dilaksanakan secara turun-menurun dari nenek moyang. Sebagai contoh yaitu tradisi Dhandangan di Kabupaten Kudus (Ismaya dan
Santoso 2019) yang telah dilaksanakan masyarakat secara turun menurun sejak zaman Sayyid Ja'far Sodiq (Sunan Kudus) yang dilakukan untuk menyambut bulan suci Ramadhan. Kemudian Buka Luwur Makam Sunan Kudus (Ismaya, 2008; Ismaya, Fathurohman, dan Setiawan 2017)

Begitupun masyarakat Desa Singocandi yang memiliki tradisi yang dilestarikan yaitu Apitan sedekah bumi yang rutin dilaksanakan pada setiap tahun di area pundhen Mbah Buyut Punjol. Santoso (2013) menyebut tradisi Apitan memiliki arti sebagai bentuk sedekah bumi, untuk mensyukuri rezeki yang telah masyarakat terima selama setahun. Lebih lanjut Nikmah (2020) menyebut bahwa dalam tradisi Apitan terdapat nilai-nilai pendidikan karakter yang dapat diperoleh diantaranya yaitu sikap religius, jujur, disiplin, cinta tanah air, toleransi, cinta damai, peduli lingkungan, peduli sosial, dan bertanggung jawab.

Tradisi Apitan Sedekah Bumi dilaksanakan pada bulan Apit atau Dzulqo'dah, disebut bulan Apit karena bulan ini terletak diantara hari raya Idul Fitri dengan hari raya Idhul Adha. Hal tersebut selaras dengan pernyataan Nikmah (2020) yang menyatakan bahwa tradisi apitan atau yang biasa disebut sedekahi bumi merupakan tradisi masyarakat yang dilaksanakan pada bulan Apit yang berada diantara dua hari raya besar Idul Fitri dengan Idul Adha.

Perayaan tradisi Apitan sedekah bumi Masyarakat Desa Singocandi dalam perspektif peneliti merupakan sebuah upaya untuk melestarikan warisan budaya sekaligus upaya untuk mengamalkan pendidikan karakter didalamnya. Hal inilah yang menjadikan peneliti tertarik untuk menggali lebih dalam mengenai alasan masyarakat Desa Singocandi masih melakukan tradisi Apitan Sedekah Bumi, serta menganalisa nilai pendidikan karakter dalam Apitan sedekah bumi di Desa Singocandi.

\section{METODE PENELITIAN}

Penelitian dilakukan menggunakan pendekatan kualitatif dengan jenis deskriptif serta metode studi lapangan. Penelitian dilakukan di Desa Singocandi, Kecamatan Kota, Kabupaten Kudus. Adapun teknik pengumpulan datanya melalui observasi, wawancara, serta studi dokumen.

Dalam penelitian ini peneliti menggunakan sumber data primer dan sumber data sekunder. Sumber data primer didapatkan 


\section{Muchamad Munawir Asyari, Erik Aditia Ismaya, dan Muhammad Noor Ahsin \\ NILAI-NILAI PENDIDIKAN KARAKTER DALAM TRADISI APITAN MASYARAKAT ... \\ WASIS : Jurnal Ilmiah Pendidikan. Volume 2 Nomor 1 Mei 2021, hlm. 34-40}

dari hasil observasi dan wawancara kepada juru kunci pundhen Mbah Buyut Punjol, perangkat desa, serta panitia Tradisi Apitan Sedekah Bumi Desa Singocandi. Sedangkan untuk sumber data sekunder diperoleh dari dokumen pendukung. Dimana dokumen pendukung yang digunakan yakni arsip desa, foto, dan laporan-laporan penelitian yang memiliki persamaan tema riset.

Pengujian keabsahan data digunakan teknik triangulasi data yang sudah diterima dari berbagai sumber atau dari beberapa teknik pengumpulan data. Sebagaimana Sugiyono (2015) menjelaskan bahwa teknik pengumpulan data secara triangulasi dibedakan menjadi dua jenis yaitu pertama triangulasi teknik pengumpulan data, kedua triangulasi sumber pengumpulan data.

Dalam penelitian ini triangulasi teknik dilakukan dengan cara menggabungkan data yang diterima dari hasil observasi, wawancara, dan dokumen. Sementara triangulasi sumber dilakukan dengan menggabungkan data hasil wawancara dari berbagai narasumber.

\section{HASIL DAN PEMBAHASAN}

A. Tradisi Apitan Masih Lestari

Alasan masyarakat Desa Singocandi masih melestarikan Tradisi Apitan Sedekah Bumi untuk mengormati jasa para leluhur bangsa Indonesia, dan sebagai ungkapan rasa syukur atas rezeki yang telah diterima masyarakat Desa Singocandi.

Narasumber bapak Sodri mengungkapkan bahwa

"Tradisi Apitan di Singocandi dilaksanakan pada setiap tahun pada tanggal 27 Dzulqo'dah atau bulan Apit, tradisi ini dilaksanakan di pundhen Mbah Buyut Punjol yang terletak di desa Singocandi RT. 2 RW. 1. Masyarakat rutin melaksanakan tradisi ini untuk menghormati para leluhur bangsa yang ada di Desa Singocandi, dimana para leluhur bangsa seperti Mbah Buyut Punjol merupakan salah seorang yang telah berjasa bagi perkembangan Desa Singocandi. Selain itu tradisi Apitan dilaksanakan sebagai bentuk ungkapan rasa syukur atas rezeki yang telah dilimpahkan Allah SWT kepada masyarakat desa Singocandi."

Berdasarkan hasil wawancara di atas diketahui bahwa tradisi Apitan dilaksanakan setiap tahun pada tanggal 27 Dzulqo'dah. Dimana masyarkat tetap melestraikan tradisi ini untuk menghormati jasa Mbah Buyut Punjol sebagai leluhur Desa Singocandi. Mbah Buyut
Punjol merupakan salah seorang tokoh ulama yang berjasa bagi warga Singocandi.

Alasan lain masyarakat Desa Singocandi selalu rutin melaksanakan tradisi Apitan yakni sebagai ungkapan rasa syukur atas rezeki yang mereka terima. Selain itu juga dengan diperingatinya kegiatan ini pada setiap tahun tradisi budaya ini akan tetap lestari sebagai warisan budaya.

Tujuan pelaksanaan tradisi apitan di Singocandi tentunya sejalan dengan ungkapan Nikmah (2020) yaitu tradisi Apitan merupakan suatu untuk mendoakan arwah leluhur yang sudah meninggal, dan sebagai bentuk syukur atasi hasil panen yang diberikan oleh Tuhan. Leluhur bangsa merupakan pahlawan yang sudah berjasa bagi negeri ini, memang sudah sepantasnya untuk kita menghormati jasa mereka.

Dalam tradisi budaya terdapat berbagai kegiatan sakral yang dilaksanakan. Dalam tradisi Apitan di Desa Singocandi sebelum adanya wabah covid-19 terdapat beberapa kegiatan yang dilaksanakan seperti beshik pundhen, tahlilan, manaqiban, Maulid Al-Barzanji, Pengajian umum, kirab budaya, dan pagelaran wayang kulit.

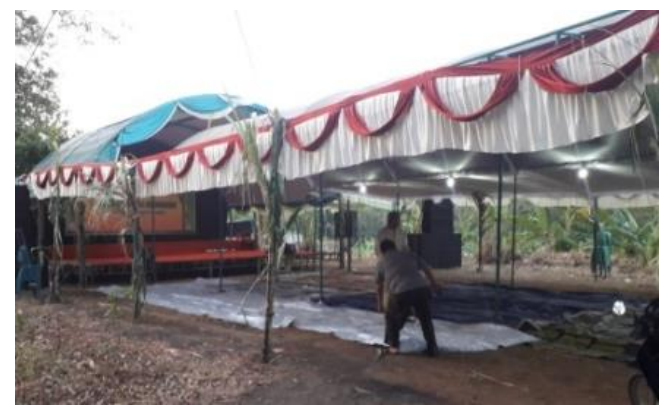

Gambar 1. Kegiatan Beshik Pundhen

Gambar di atas merupakan kegiatan Beshik Pundhen yang dilakukan di makam Mbah Buyut Punjol. Kegiatan Beshik Pundhen dilakukan oleh panitia Apitan Sedekah Bumi Singocandi.

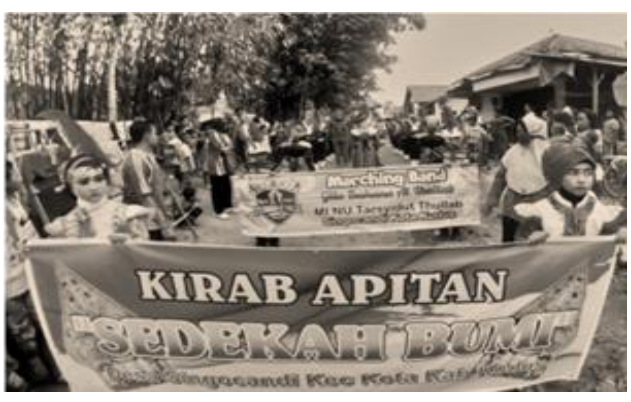

Gambar 2. Kirab Apitan 


\section{Muchamad Munawir Asyari, Erik Aditia Ismaya, dan Muhammad Noor Ahsin \\ NILAI-NILAI PENDIDIKAN KARAKTER DALAM TRADISI APITAN MASYARAKAT ... \\ WASIS : Jurnal Ilmiah Pendidikan. Volume 2 Nomor 1 Mei 2021, hlm. 34-40}

Dapat diketahui dari gambar di atas bahwa dalam Apitan di Singocandi terdapat kegiatan kirab budaya. Kegiatan ini diikuti siswa-siswi tingkat Madrasah Ibtida'iyah.

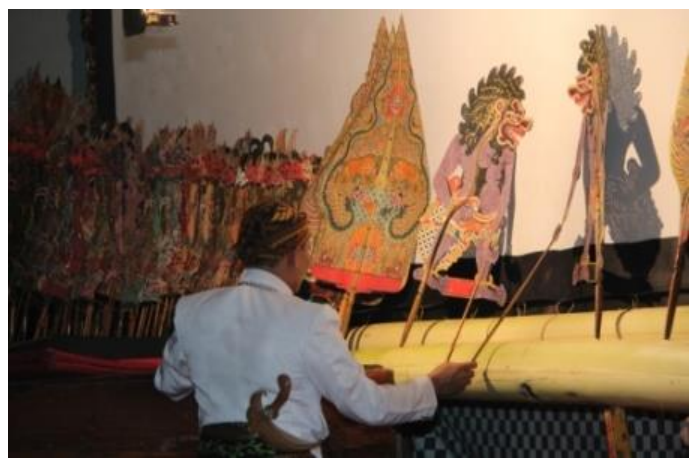

Gambar 3. Pagelaran Wayang Kulit

Panitia menggelar wayangan sebagai upaya pelestarian kesenian bangsa Indonesia. Adanya wabah Covid-19, pemerintah mengatur tentang pembatasan jumlah orang, dan pembatasan jarak dalam sebuah kegiatan. Pemerintah desa Singocandi bersama masyarakat memutuskan agar tradisi Apitan desa Singocandi diadakan dengan sederhana, sebagaimana dijelaskan narasumber Sodri sebagai berikut

"Pelaksanaan tradisi Apitan sedekah bumi di Desa Singocandi untuk tahun ini berhubungan adanya wabah Covid-19, kegiatannya dilaksanakan secara sederhana dalam bentuk tahlilan dan manaqiban, dan dengan pembatasan jumlah undangan dan penghapusan kegiatan yang menimbulkan kerumunan secara besar".

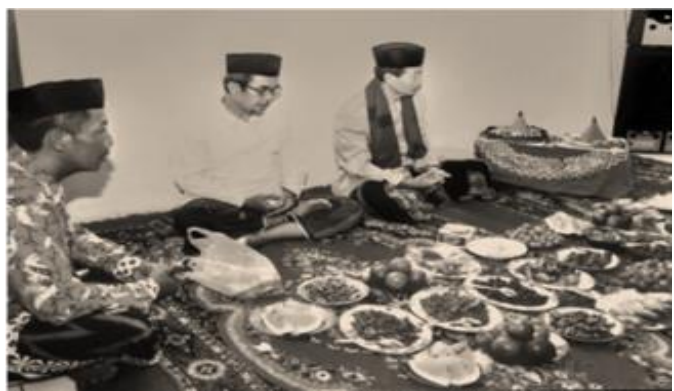

Gambar. 4 Khajatan Apitan

Dalam situasi pandemi covid-19 tentunya kegiatan Apitan di Singocandi tidak dapat dilaksanakan seperti biasa. Dimana tampak pada gambar bahwa Apitan di Singocandi dilakukan secara sederhana.
Tradisi apitan sedekah bumi di Singocandi bermakna sebagai bentuk slametan agar terhindar dari wabah penyakit salah satunya adalah covid-19. Makna lain dari tradisi apitan sedekah bumi adalah syukuran atas rezeki yang telah dilimpahkan Allah SWT kepada masyarakat Singocandi. Selain sebagai slametan dan syukuran tradisi apitan sedekah bumi di Singocandi juga digunakan sebagai sarana mengamalkan pendidikan karakter kepada masyarakat Singocandi.

B. Nilai Pendidikan Karakter dalam Tradisi Apitan.

\section{Religius}

Karakter religius merupkan sikap yang berkaitan dengan ajaran agama Islam. Sebagaimana narasumber bapak Sodri mengungkapkan bahwa

"Salah satu nilai pendidikan yang terdapat dalam tradisi Apitan sedekah bumi adalah penanaman nilai religius kepada masyarakat dan juga anak-anak. Sikap religius diwujudkan seperti pada kegiatan tahlilan ketika kyai mengajak masyarakat untuk berdo'a dan berdzikir meminta kepada Allah SWT supaya terhindar dari wabah dan bencana, hal ini menunjukan bahwa sebagai orang yang beriman kita hanya bisa meminta perlindungan dari Allah SWT."

Ungkapan di atas menunjukan bahwa dalam tradisi Apitan di Desa Singocandi diwujudkan ketika berdo'a sebagai umat Islam kita hanya dapat meminta pertolongan kepada Allah SWT. Hasil penelitian yang dilakukan senada dengan riset Ismaya, Permana, dan Setyowati (2017) yang menemukan bahwa berdasarkan topografi wilayah Dukuh Masin, lahir sebuah cerita rakyat Raden Ayu Nawangsih dan Raden Bagus Rinangku. Pada hakekatnya, cerita rakyat ini merupakan sebuah upaya melestarikan lingkungan. Dalam kajian folklor, cerita rakyat Raden Ayu Nawangsih dan Raden Bagus Rinangku memiliki nilai pendidikan, keagamaan dan sejarah.

\section{Jujur}

Karakter jujur berkaitan dengan akhlak manusia agar selalu berbuat baik serta tidak membohongi orang lain. Sebagaimana diungkapkan oleh narasumber bapak Sodri bahwa:

"Karakter jujur ditanamkan dalam tradisi Apitan sedekah bumi, hal tersebut diwujudkan dalam pengelolan dan laporan 


\section{Muchamad Munawir Asyari, Erik Aditia Ismaya, dan Muhammad Noor Ahsin \\ NILAI-NILAI PENDIDIKAN KARAKTER DALAM TRADISI APITAN MASYARAKAT ... WASIS : Jurnal Ilmiah Pendidikan. Volume 2 Nomor 1 Mei 2021, hlm. 34-40}

dana bantuan untuk tradisi Apitan sedekah bumi. Biasanya panitia yang telah terbentuk akan meminta bantuan kepada masyarakat dan juga perusahaan di Kudus, panitia harus melaporkan perolehan dana dengan transparan kepada seluruh panitia dan masyarakat desa."

Ungkapan di atas menunjukan bahwa Apitan di Singocandi karakter jujur ditanamkan dengan panitia menyampaikan perolehan dana secara transparan untuk menghormati donatur.

\section{Toleransi}

Indonesia sangat kaya dengan keragaman budaya, sehingga untuk menjaga persatuan diperlukan sikap toleransi. Sebagaimana diungkapkan narasumber bapak Sodri bahwa:

"Masyarakat di Desa Singocandi sangatlah beragam dari segi agama, dan juga organisasi agama yang berbeda-beda, namun hal tersebut tidak menutup kebersamaan dalam melaksanakan kegiatan Apitan sedekah bumi di desa Singocandi. Salah satu contohnya pada kegiatan ini baik warga Nahdhatul Ulama' dan Muhammadiyah saling bergotong royong dalam melancarkan tradisi ini."

Ungkapan di atas menunjukan bahwa toleransi masyarakat Desa Singocandi diwujudkan dalam gotong royong antara warga Nahdhatul Ulama' dan Muhammadiyah dalam menjalankan tradisi Apitan sedekah bumi.

\section{Disiplin}

Disiplin dapat dikatakan sebagai perilaku tepat waktu dan taat dengan peraturan. Seperti yang diungkapkan narasumber bapak Sodri bahwa:

"Dalam pelaksanaan kegiatan tradisi Apitan sedekah bumi Desa Singocandi setiap panitia yang mendapatkan tugas seperti seksi acara, MC, dan seksi perlengkapan harus disiplin datang tepat waktu dan menyiapkan segala perlengkapan yang dibutuhkan. Tujuannya supaya acara dapat berjalan tepat waktu dan lancar, sehingga acara tidak akan mengecewakan masyarakat."

Ungkapan di atas menunjukan bahwa karakter disiplin diwujudkan ketika panitia yang mendapatkan tugas dalam pelaksanaan tradisi apitan di Singocandi harus datang tepat waktu. Hasil penelitian yang dilakukan senada dengan riset Nihayati, Ismaya, dan Oktavianti (2021) yaitu bahwa disiplin merupakan karakter baik yang harus selalu ditanamkan pada generasi muda melalu berbagai kegiatan.

\section{Kreatif}

Karakter kreatif dapat dikatakan sebagai sikap seseorang dalam membentuk suatu pembaharuan terhadap sesuatu yang sudah ada sebelumnya. Seperti yang diungkapkan oleh narasumber bapak Masfu'i bahwa:

"Untuk menarik minat pengunjung supaya tidak merasa bosan dengan kegiatan dalam tradisi Apitan di Desa Singocandi, panitia telah melakukan pembaharuan terhadap kegiatan kirab budaya. Pada awalnya kirab budaya hanya melakukan arak-arakan sayursayuran dan buah-buahan, panitia disini kreatif karena mencoba memasukan kesenian drum band pada kirab budaya tradisi Apitan."

Ungkapan di atas menunjukan bahwa karakter kreatif diwujudkan ketika panitia memasukan kesenian drum band yang sebelumnya tidak ada pada kirab budaya tradisi Apitan Desa Singocandi.

\section{Cinta tanah air}

Karakter cinta tanah air dapat dikatakan sebagai sikap seorang yang selalu menjaga tempat kelahiran dan tinggalnya. Seperti yang diungkapkan narasumber Sodri bahwa:

"Warisan budaya merupakan peninggalan dari leluhur bangsa yang wajib kita jaga dan lestarikan, tindakan tersebut sebagai bentuk cinta kita terhadap tanah air Indonesia, seperti tetap menjaga keberadaan tradisi apitan sedekah bumi di Singocandi merupakan salah satu bentuknya."

Ungkapan di atas menunjukan bahwa karakter cinta tanah air diwujudkan dalam upaya yang dilakukan masyarakat untuk melestarikan tradisi budaya sebagai warisan dari leluhur bangsa. Hasil riset yang dilakukan memiliki persamaan dengan penelitian Ismaya dan Romadlon (2017) yaitu bahwa karakter cinta tanah air atau semangat kebangsaan atau nasionalisme samasama ditemukan pada riset yang dilakukan serta riset Ismaya dan Romadlon (2017).

\section{Peduli sosial}

Karakter peduli sosial diartikan sebagai sikap tolong menolong kepada orang lain, Seperti tyang diungkapkan oleh narasumber Sodri bahwa:

"Semua kegiatan disini dilakukan secara gotong royong dan saling membantu satu sama lain. Memang kadang ada beberapa warga yang tidak bisa ikut serta dalam gotong royong karena sedang bekerja atau diluar kota, panitia juga memaklumi hal tersebut 


\section{Muchamad Munawir Asyari, Erik Aditia Ismaya, dan Muhammad Noor Ahsin \\ NILAI-NILAI PENDIDIKAN KARAKTER DALAM TRADISI APITAN MASYARAKAT ... WASIS : Jurnal Ilmiah Pendidikan. Volume 2 Nomor 1 Mei 2021, hlm. 34-40}

apalagi mereka yang tidak ikut juga masih membantu dalam bentuk lain seperti jajanan/minuman."

Ungkapan di atas menunjukan bahwa karakter peduli sosial dalam tradisi apitan desa Singocandi diwujudkan dalam gotong royong dan saling membantu. Warga yang tidak bisa ikut membantu tenaga juga ikut membantu dalam bentuk jajanan/minuman. Hasil riset yang dilakukan senada dengan penelitian Nuha, Ismaya, dan Fardani (2021) yaitu bahwa adanya nilai peduli sosial pada riset yang dilakukan.

\section{Peduli lingkungan}

Peduli lingkungan adalah upaya kita untuk menjaga lingkungan. Ismaya (2014) menjelaskan lebih jauh, lebih mendasar dan lebih penting dari sekedar aturan hukum dalam pengelolaan dan perlindungan lingkungan adalah manusiannya sebagai pelaksana, yang mana individu harus memiliki rasa cinta dan peduli lingkungan. Seperti tyang diungkapkan Masfu'i bahwa:

"Sebelum semua kegiatan dalam acara apitan sedekah bumi berlangsung, panitia bersama masyarakat desa melakukan beshik pundhen, kegiatan ini dilakukan untuk menumbuhkan rasa cinta dengan lingkungan dan sikap peduli lingkungan kepada masyarakat Singocandi. Dalam kegiatan ini seluruh area pundhen Mbah Buyut Punjol dibersihkan, baru setelah itu tratak dan panggung dipasang guna menunjang seluruh kegiatan yang akan dilaksanakan."

Ungkapan di atas menunjukan bahwa karakter peduli lingkungan dalam tradisi apitan diwujudkan ketika masyarakat membersihkan pundhen Mbah Buyut Punjol, supaya pundhen terlihat bersih, rapi dan asri. Hasil penelitian yang dilakukan senada dengan riset Ismaya, Permana, dan Setyowati (2017) bahwa pada hakekatnya cerita rakyat Raden Ayu Nawangsih dan Raden Bagus Rinangku merupakan sebuah upaya melestarikan lingkungan. Dalam kajian folklor, cerita rakyat Raden Ayu Nawangsih dan Raden Bagus Rinangku memiliki nilai pendidikan, keagamaan dan sejarah.

\section{SIMPULAN}

Dapat disimpulkan bahwa tradisi Apitan di Singocandi memiliki makna slametan dengan harapan masyarakat Singocadi terhindar dari wabah seperti covid-19. Makna lain dalam tradisi yaitu syukuran sebagai ungkapan rasa syukur atas rezeki dan kesehatan yang telah diberikan oleh Allah SWT kepada masyarakat Singocandi.
Kegiatan Apitan di Singocandi menunjukan bahwa terdapat pengamalan pendidikan karakter yang terkadung. Kegiatan dalam tradisi Apitan Desa Singocandi ialah beshik pudhen, tahlilan, manaqiban, maulid albarzanji, pengajian umum, kirab budaya, serta wayangan.

Karakter yang diamalkan dalam Apitan di Singocandi yakni religius, jujur, toleransi, disiplin, kreatif, cinta tanah air, peduli sosial, serta peduli lingkungan. Pengamalan pendidikan karakter sangat bermanfaat bagi masyarakat Singocandi terutama bagi generasi milenial, apalagi sekarang ini terjadi degredasi karakter di Indonesia.

\section{DAFTAR PUSTAKA}

Kurniasih, Imas dan Berlin Sani. 2017. Pendidikan Karakter Internalisasi Pembelajaran di Sekolah. Yogyakarta: Kata Pena.

Ismaya, Erik Aditia. 2014. Membangun Generasi Emas Indonesia 2045 Yang Cinta dan Peduli Lingkungan. Prosiding Seminar Nasional Pengelolaan Sumber Daya Alam dan Lingkungan dengan tema "Pembangunan Berkelanjutan dalam Perspektif Ketahanan Energi, Pengelolaan Lingkungan dan Pengelolaan Bencana”. Semarang : Universitas Diponegoro Semarang Program Studi Magister Ilmu Lingkungan.

Ismaya, Erik Aditia dan Romadlon, Farid Noor. 2017. Strategi Membentuk Karakter Semangat Kebangsaan Anggota Ambalan Kyai Mojo Dan Nyi Ageng Serang. REFLEKSI EDUKATIKA : Jurnal Ilmiah Kependidikan, 7 (2): 140-144.

Ismaya, Erik Aditia., Permana, Septian Aji dan Setyowati, Dewi Liesnoor. 2017. MAKNA DIBALIK LEGENDA: Kearifan Lokal Masyarakat Masin dalam Melestarikan Lingkungan. Prosiding Seminar Nasional Pembelajaran Bahasa dan Sastra Indonesia Berbasis Kearifan Lokal dalam Pembentukan Karakter Bangsa, 18 Mei 2017, 55-62. Kudus: Badan Penerbit Universitas Muria Kudus.

Ismaya, Erik Aditia., Fathurohman, Irfai., dan Setiawan, Deka. 2017. Makna Dan Nilai 
Muchamad Munawir Asyari, Erik Aditia Ismaya, dan Muhammad Noor Ahsin

NILAI-NILAI PENDIDIKAN KARAKTER DALAM TRADISI APITAN MASYARAKAT ...

WASIS : Jurnal Ilmiah Pendidikan. Volume 2 Nomor 1 Mei 2021, hlm. 34-40

Buka Luwur Sunan Kudus (Sumbangan Pemikiran Mewujudkan Visi Kampus Kebudayaan). KREDO: Jurnal Ilmiah Bahasa dan Sastra, 1 (1): 44-57.

Ismaya, Erik Aditia dan Santoso. 2019. Tradisi Dandangan Sebagai Kajian Pembelajaran Dalam Mendukung Pencapaian Visi Universitas Kebudayaan (Studi pada Mata Kuliah Konsep Ilmu Pengetahuan Sosial). REFLEKSI EDUKATIKA : Jurnal Ilmiah Kependidikan, 10 (1): 128-137.

Kemendiknas, 2011. Panduan Pelaksanaan Pendidikan Karakter. Jakarta: Kementerian Pendidikan Nasional.

Kiftiyah, dkk. 2020. Penanaman Rasa Syukur Melalui Tradisi Sedekah Bumi Di Desa Tegalarum, Demak. Dinamika Sosial Budaya, 22 (1): 105-117.

Nihayati, I., Ismaya, E., \& Oktavianti, I. (2021). Pendidikan Karakter Disiplin Pada Santri Pondok Pesantren Slaf Terpadu Bahjatur Roghibiin Kudus. Jurnal Inovasi Penelitian, 1 (11): 2395-2402.

Nikmah, Faridhatun. 2020. Nilai-nilai Pendidikan Karakter Dalam Tradisi Apitan Di Desa Serangan. Handep Jurnal Sejarah dan Budaya, 3 (2): 215-232.

Nuha, Siti Ulin., Ismaya, Erik Aditia., dan Fardani, Much Arsyad. 2021. Nilai Peduli Sosial Pada Film Animasi Nussa Dan Rara. Jurnal Riset Pendidikan Dasar, 04 (1): 17-23.

Pambudi. 2014. Upaya Pelestarian Tradisi Baritan Dalam Upacara Adat Sedekah Bumi Di Desa Kedung Waringin. Jurnal Prodi Pendidikan Bahasa dan Sastra Jawa, 4 (4): 15-16.

Putri, S. R. A., Ismaya, Erik Aditia., and Fardani, Much. Arsyad. 2021. Phenomenon Of Verbal Bullying In The Pedawang Society. NATURALISTIC : Jurnal Kajian Penelitian Pendidikan Dan Pembelajaran, 5 (2): 792-796.

Romadlon, Farid Noor and Ismaya, Erik Aditia. 2015. Education Model and Formation of Indonesia Youth Character Through Scout
Movement. Proceeding The 4th International Conference On Education and Social Science (ICESS) Faculty of Social Sciences, Semarang State University (UNNES), On May 13, 2015

Sari, Mita Puspita dan Brata, Nugroho Trisnu. 2018. Hubungan Antara Mitos Pageblug dan Tradisi Apitan pada Masyarakat Jawa di Semarang. Jurnal Patrawidya, 19 (2): 97-106.

Santoso, Heri Dwi. 2013. Apitan: Pelestarian Tradisi Agraris Lokal Masyarakat Jawa. Lensa: Kajian Kebahasaan, Kesusastraan, dan Budaya, 3 (2): 77-85.

Setiawati, Debi. 2019. Slametan dalam Spritualisme Orang Jawa pada masa lalu sampai sekarang. MahaRsi Jurnal Pendidikan, 1 (1): 76-88.

Sudardi, Bani dan Afiliasi Ilafi. 2017. Hegemoni Budaya dalam Tradisi Manaqiban. Jurnal Madaniyah, 1 (12): 188-203.

Sugiyono. 2015. Metode Penelitian Pendidikan: Pendekatan Kuantitatif, Kualitatif, dan $R \& D$. Bandung: Alfabeta. 